\title{
Aggressiveness of the tall cell variant of papillary thyroid carcinoma is independent of the tumor size and patient age
}

\author{
ROCÍO VILLAR-TAIBO ${ }^{1}$, DIEGO PETEIRO-GONZÁLEZ ${ }^{2}$, JOSÉ MANUEL CABEZAS-AGRÍCOLA ${ }^{3}$, \\ ELVIN ALIYEV $^{4,5}$, FRANCISCO BARREIRO-MORANDEIRA ${ }^{6}$, \\ CLARA RUIZ-PONTE $^{7}$ and JOSÉ M. CAMESELLE-TEIJEIRO ${ }^{5}$
}

\author{
${ }^{1}$ Department of Endocrinology, University of León Hospital, León 24071; ${ }^{2}$ Department of Endocrinology, \\ Hospital El Bierzo, Ponferrada 24411; ${ }^{3}$ Department of Endocrinology, Clinical University Hospital, Faculty of Medicine, \\ Galician Healthcare Service, University of Santiago de Compostela, Santiago de Compostela 15706, Spain; \\ ${ }^{4}$ Department of Pediatric Surgery, 'Federico Gomez' Children's Hospital, México City 06720, México; \\ Departments of ${ }^{5}$ Anatomic Pathology and ${ }^{6}$ Surgery, Clinical University Hospital, Faculty of Medicine, \\ Galician Healthcare Service, University of Santiago de Compostela, Santiago de Compostela 15706; \\ ${ }^{7}$ Galician Public Foundation of Genomic Medicine, Centre for Biomedical Network \\ Research on Rare Diseases, Santiago de Compostela 15706, Spain
}

Received June 15, 2016; Accepted November 25, 2016

DOI: $10.3892 / 01.2017 .5948$

\begin{abstract}
The tall cell variant (TCV) of papillary thyroid carcinoma (PTC) is characterized by tall columnar cells with a height of at least three times their width. TCV usually presents at an older age, has a larger size and exhibits more extrathyroidal extension and metastases than classical PTC. The current study compared TCV with the classical and follicular variants (CaFVs) of PTC to determine if, irrespective of the age at diagnosis and tumor size, TCV is more aggressive than its classical and follicular counterparts. A total of $16(3.66 \%)$ patients with TCV were identified in a series of 437 patients with PTC from the Clinical University Hospital (Santiago de Compostela, Spain) between 1990 and 2010. The patient clinicopathological features and B-Raf proto-oncogene $(B R A F)^{\mathrm{V} 600 \mathrm{E}}$ mutational status were compared with 34 cases of CaFVs of PTC matched for tumor size and patient age. The TCV series included 11 females and 5 males aged 15-74 years (median, 57 years). In total, 15 (93.8\%) patients underwent total or near-total thyroidectomy, 1 underwent lobectomy and $5(31.3 \%)$ underwent lymph node dissection. In the TCV series, the tumor size ranged from 5-45 mm (median, $19 \mathrm{~mm}$ ). Compared with the CaFVs, the TCV of PTC exhibited a
\end{abstract}

Correspondence to: Dr José M. Cameselle-Teijeiro, Department of Anatomic Pathology, Clinical University Hospital, Faculty of Medicine, Galician Healthcare Service, University of Santiago de Compostela, Travesía Choupana s/n, Santiago de Compostela 15706, Spain

E-mail: josemanuel.cameselle@usc.es

Key words: thyroid, papillary carcinoma, tall cell variant, aggressiveness, size, age, B-Raf proto-oncogene significantly higher prevalence of extrathyroidal extension [9/16 (56.3\%) vs. 5/34 (14.7\%) cases; $\mathrm{P}=0.007]$, lymph node metastases [9/16 (56.3\%) vs. 9/34 (26.4\%) cases; $\mathrm{P}=0.04]$, stage III/IV at presentation [10/16 (62.5\%) vs. 7/34 (20.5\%) cases; $\mathrm{P}=0.009]$ and $B R A F^{\mathrm{V} 600 \mathrm{E}}$ mutation $[12 / 16(80.0 \%)$ vs. $7 / 25(28.0 \%)$ cases; $\mathrm{P}=0.004]$. The TCV series also harbored more multifocal papillary carcinomas (50.0\% vs. $26.4 \%$ ), lymphovascular invasion (37.5\% vs. $29.4 \%$ ) and distant metastases $(6.2 \%$ vs. $0.0 \%)$, as compared with the matched patient cohort. In conclusion, the TCV of PTC is frequently associated with $B R A F^{\mathrm{V} 600 \mathrm{E}}$ mutation and is more aggressive than the CaFVs of PTC, regardless of tumor size and patient age at diagnosis.

\section{Introduction}

Papillary thyroid carcinoma (PTC) is the most prevalent form of thyroid cancer, with an incidence that has continued to increase globally in recent decades (1). This tumor consists of a number of histological variants, the most common of which are conventional (classical) PTC, follicular variant PTC and tall cell variant (TCV) PTC (2). TCV PTC was initially described in 1976 by Hawk and Hazard (3) and is now an established variant composed of cells that are at least three times taller than they are wide, and which occasionally exhibit an abundant eosinophilic cytoplasm and basally oriented nuclei $(4,5)$. The 2004 World Health Organization classification of tumors defined a PTC as TCV if it is composed predominantly of tall cells (6), and the majority of experts consider that a tumor may contain $\geq 50 \%$ tall-cell features to be classified as the TCV of PTC $(4,5,7)$. However, there remains no general consensus on this classification (8-10).

TCV PTC has a relatively higher predominance in males than classical PTC, occurs at an older age and is considered an aggressive variant $(5,10)$. Patients with TCV exhibit poorer 
survival than those with classical PTC $(5,10)$. The tall-cell feature alone remains a significant prognostic factor for disease-specific mortality when the major prognostic factors for thyroid cancer are controlled for, including age and extrathyroidal extension (11). In a study of 12 cases of TCV PTC, this tumor type had an aggressive clinical course and a poorer prognosis, compared with classical PTC, in patient populations with a similar age and sex distribution, duration of follow-up and tumor size (12). The patient prognosis also remains less favorable in cases without extrathyroidal extension (13). A large multicenter study demonstrated varied prognostic risk for the three major PTC variants, establishing a risk order for PTC as follows: TCV PTC $>$ classical PTC $>$ follicular variant PTC (14). This previous study demonstrated clinical implications for the management of PTC based on the specific variant (14).

In the present study, the main clinicopathological features and the B-Raf proto-oncogene (BRAF) mutational status of a series of TCV PTC with classical and follicular variants (CaFVs) of PTC (matched in size and age) were compared in order to determine if, regardless of patient age at diagnosis and the tumor size, TCV is more aggressive than its classical and follicular counterparts.

\section{Materials and methods}

Patient selection. The hospital database was searched for all cases diagnosed as PTC and treated at the Clinical University Hospital (Santiago de Compostela, Galicia, Spain) between January 1st, 1990 and December 31st, 2010. PTCs were re-reviewed according to the criteria of the World Health Organization international classification for thyroid tumors (6) by one of the co-authors (J.M.C.-T.), a pathologist with special expertise in thyroid tumors who was blinded to the clinical outcomes of all patients involved. The tall cells were defined as tall columnar cells whose height was at least three times their width. A tumor was classified as TCV PTC if it contained $\geq 50 \%$ tall cells (5-7). To avoid selection bias, and due to their highly indolent behavior (15), cases of encapsulated follicular variant of PTC were excluded from the current study. For the same reasons, all tumors with $\geq 3$ mitoses/10 high-power fields or necrosis with poorly differentiated-like behavior $(6,16)$ were also excluded. Written informed consent was obtained from all patients. The Independent Ethics Committee of Galicia (Galician Healthcare Service; SERGAS) approved the study protocol, which was conducted in accordance with the Declaration of Helsinki and applicable Spanish laws.

Clinical, histopathological, immunohistochemical and molecular parameters. The following histopathological parameters were assessed: Carcinoma size, multifocality, infiltration of the two thyroid lobes (bilaterality), vascular invasion, perineural infiltration, status of the resection margins, presence of tumor cells invading beyond the thyroid capsule into perithyroid soft tissue or organs (extrathyroid tumor extension) and the presence of metastatic lymph nodes. The largest dimension of the carcinoma was determined by a review of the gross pathology report and direct measurement of the tumor on the microscopic slides. The patient's electronic medical records were reviewed for the age at diagnosis, type of surgery (including re-interventions) and administration of radioactive iodine therapy. Staging was performed according to the American Joint Committee on Cancer staging manual 7th edition (17). The mean follow-up for all patients was 59.6 months [standard deviation (SD), 44.7 months].

Immunohistochemical studies were performed on $4 \mu \mathrm{m}$-thick paraffin-embedded representative tumor sections from thyroidectomy specimens. A peroxidase-conjugated labeled dextran polymer (EnVision FLEX/HRP; Dako; Agilent Technologies, Inc., Santa Clara, CA, USA) was used with 3,3'-diaminobenzidine as the chromogen in the Autostainer Link 48 (Dako; Agilent Technologies, Inc.) according to the manufacturer's protocol. Deparaffinization, rehydration and target retrieval $(\mathrm{pH}$ 6.0) were performed on a PT Link pretreatment module (Dako; Agilent Technologies, Inc.). Subsequently, samples were incubated with primary antibodies against thyroglobulin (catalog no. IR509; rabbit polyclonal; ready to use; $\mathrm{pH}$ 6.0; Dako; Agilent Technologies, Inc.) and calcitonin (catalog no. IR515; polyclonal; ready to use; $\mathrm{pH}$ 9.0; Dako; Agilent Technologies, Inc.) at room temperature for 20 and $15 \mathrm{~min}$, respectively. An immunoglobulin fraction of normal rabbit serum supplied in $0.05 \mathrm{~mol} / \mathrm{l} \mathrm{NaCl}$, 15 and $\mathrm{mmol} / \mathrm{l} \mathrm{NaN} 3$ (pH 7.2), and containing stabilizing protein (catalog no. IR600; Dako; Agilent Technologies, Inc.) was used as the negative control. Tissue sections containing a medullary carcinoma (calcitonin) and normal thyroid (thyroglobulin) obtained from the Carlos III Health Institute (Madrid, Spain; TIROCHUS collection no. 0003960), were simultaneously evaluated as positive controls for thyroglobulin and calcitonin. The slides were counterstained with hematoxylin. The staining for thyroglobulin and for calcitonin was considered positive only if the cytoplasm of tumor cells had been stained brown with the chromogen following microscopic examination (Olympus BX41TF; Olympus Corporation, Tokyo, Japan).

For BRAF molecular genetic analysis, tumor tissue was identified and marked on the hematoxylin and eosin-stained glass slides by the pathologist. Genomic DNA was extracted from the paraffin-embedded tumor tissue using a QIAamp DNA Mini kit (Qiagen Inc., Valencia, CA, USA) according to the manufacturer's protocol. DNA samples were screened for mutations in exons 11 and 15 of the BRAF gene (National Center for Biotechnology Information reference sequence, NM_004333). Exons 11 and 15 of the $B R A F$ gene were amplified by polymerase chain reaction (PCR) using 50-70 ng of genomic DNA. Each 12.5- $\mu$ l reaction consisted of 1X PCR buffer (catalog no. M7801; Promega Corporation, Madison, WI, USA), $3 \mathrm{mM} \mathrm{MgCl} 2,200 \mu \mathrm{M}$ deoxynucleotides, $0.5 \mu \mathrm{M}$ of each primer and 0.6 U GoTaq Flexi DNA Polymerase (catalog no. M7801; Promega Corporation). Primer sequences were as follows: Exon 11, forward 5'-GCATAAGGTAATGTACTT AGGGTGAA-3' and reverse 5'-AACAGTGAATATTTCCTT TGATGAT-3'; and exon 15, forward 5'-TCATAATGCTTG CTCTGATAGG-3' and reverse 5'-GGCCAAAAATTTAAT CAGTGGA-3' (18). The thermocycling conditions consisted of an initial denaturation at $94^{\circ} \mathrm{C}$ for $3 \mathrm{~min} ; 35$ cycles at $94^{\circ} \mathrm{C}$ for $30 \mathrm{sec}, 30 \mathrm{sec}$ of annealing at $60^{\circ} \mathrm{C}$ for exon 15 and at $55^{\circ} \mathrm{C}$ for exon 11 , and $72^{\circ} \mathrm{C}$ for $45 \mathrm{sec}$; and a final extension at $72^{\circ} \mathrm{C}$ for $7 \mathrm{~min}$. The PCR products were bidirectionally sequenced 

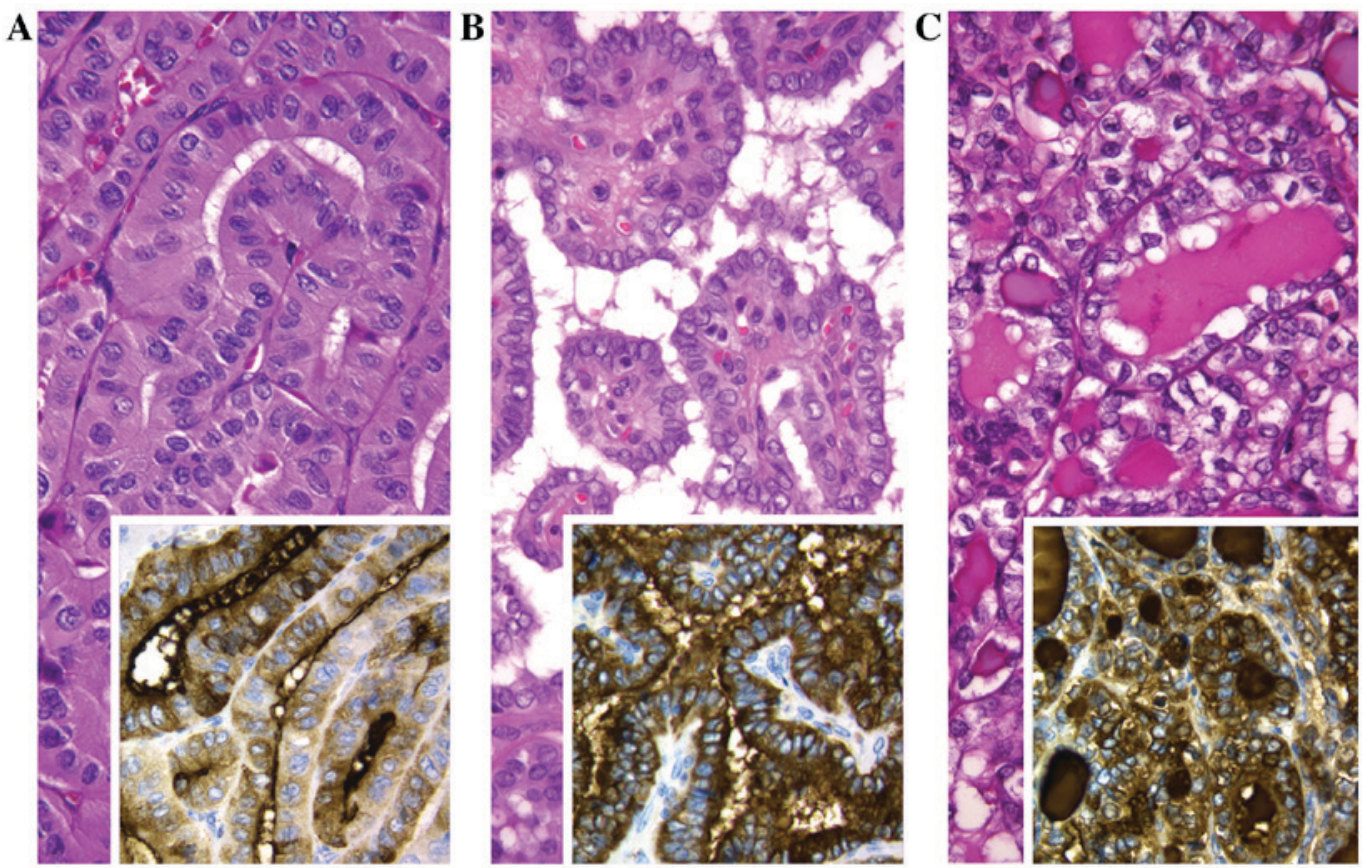

Figure 1. (A) In the tall cell variant of PTC, the tumor cells are 'tall', their cytoplasm is oncocytic and the pattern of growth is that of highly packed, regimented papillae. (B) The classical variant of PTC is composed of branching papillae formed by a central fibrovascular stalk covered by a neoplastic epithelial lining. (C) In the follicular variant of PTC, the pattern of growth is follicular throughout. Hematoxylin and eosin staining; original magnification, $\mathrm{x} 400$. All these variants of PTC were positive for thyroglobulin in the immunohistochemical study (insets; magnification, x400). PTC, papillary thyroid carcinoma.

using capillary electrophoresis (3730 DNA Analyzer; Applied Biosystems; Thermo Fisher Scientific, Inc., Waltham, MA, USA) with the aforementioned primers.

Statistical analysis. Statistical analysis was conducted using SPSS version 18.0 (SPSS Inc., Chicago, IL, USA). The TCV PTC cohort $(n=16)$ was compared with the matched series of classical $(n=18)$ and follicular $(n=16)$ variants of PTC. Data are presented as the mean \pm SD or as a percentage. Categorical variables were compared using $\chi^{2}$ analysis, whereas continuous variables were compared using student's $t$-tests or Mann Whitney $\mathrm{U}$ tests, as appropriate. $\mathrm{P}<0.05$ was considered to indicate a statistically significant difference.

\section{Results}

Clinicopathological features. In total, 16 (3.66\%) patients with TCV PTC were identified in a series of 437 patients with PTC. The TCV series included 11 females and 5 males aged 15-74 years (median, 57 years). Table I presents the clinicopathological features of the TCV PTC series in comparison with the control group of CaFVs of PTC. The clinicopathological features and $B R A F^{\mathrm{V} 600 \mathrm{E}}$ mutational status of the TCV PTC series were compared with the 34 cases of CaFVs of PTC matched for tumor size and age at diagnosis (Table II).

In the TCV PTC series, the tumor size ranged from 5-45 $\mathrm{mm}$ (median, $19 \mathrm{~mm}$ ). Extrathyroidal extension was present in $9(56.3 \%)$ cases and lymph node metastases were detected in $9(56.3 \%)$ cases. In total, 8 patients $(50.0 \%)$ had multifocal papillary carcinomas, with lymphovascular invasion in $6(37.5 \%)$ cases and distant metastases in $1(6.2 \%)$ case. A total of 10 patients $(62.5 \%)$ presented at stage III/IV. At presentation, one patient in the TCV PTC group had distant metastases, whereas no distant metastasis was detected in the control group. During follow-up, two patients with TCV PTC developed metastases (cervical lymph node metastases in one case and lung metastases in one case), and two other patients with TCV PTC succumbed to the disease. No metastases or disease-associated mortalities were observed in the control group. At the end of the study, a lower percentage of disease-free patients and slightly higher rate of recurrence was observed in the TCV PTC group by comparison with the control group $(50.0 \%$ vs. $85.3 \%$ disease-free patients, $\mathrm{P}=0.02 ; 37.5 \%$ vs. $11.7 \%$ rate of recurrence, $\mathrm{P}=0.08$, respectively). The survival rate in patients with TCV PTC was $87.5 \%$, compared with $97.0 \%$ in the control group; however, this difference was not statistically significant $(\mathrm{P}=0.1)$.

The control group exhibited less extrathyroidal extension and lymph node metastases: $5(14.7 \% ; \mathrm{P}=0.007)$ and 9 (26.5\%; $\mathrm{P}=0.04)$ cases, respectively. In total, 9 (26.5\%) tumors were multifocal, with lymphovascular invasion in $10(29.4 \%)$, no distant metastases and 7 (20.5\%) patients vs. $10(62.5 \%)$ patients presenting at stage III/IV $(\mathrm{P}=0.04)$.

Immunohistochemical and molecular findings. In accordance with their follicular cell derivation, in the two series, all tumors were positive for thyroglobulin and negative for calcitonin (Fig. 1). The BRAF mutational analysis was performed in 40 cases. No correlation was detected between age or tumor size and the mutational status of the $B R A F$ gene. The $B R A F^{V 600 E}$ mutation was higher in the TCV PTC series compared with the CaFVs of PTC series [12/15 (80.0\%) vs. $7 / 25(28.0 \%)$ cases; $\mathrm{P}=0.004)$. The $B R A F^{V 600 E}$ mutation was associated with extrathyroidal extension $(\mathrm{P}=0.009)$, lymph node metastases $(\mathrm{P}=0.028)$ and the advanced-stage of disease $(\mathrm{P}=0.049) . B R A F^{V 600 E}$ mutation was present in the tumor of 
Table I. Clinicopathological features at presentation according to the subtype of PTC.

\begin{tabular}{|c|c|c|c|}
\hline Variable & TCV of PTC $(n=16)$ & CaFVs of PTC $(n=34)$ & P-value \\
\hline Female gender $(\%)$ & $11(68.8)$ & $28(82.4)$ & 0.400 \\
\hline Age, years (SD) & $57(18.5)$ & $50.8(15.7)$ & 0.100 \\
\hline Follow-up time, months (\%) & $15(93.8)$ & $34(100.0)$ & 0.100 \\
\hline Type of surgery, n (\%) & & & 0.100 \\
\hline Lobectomy & $1(6.2)$ & $1(2.9)$ & \\
\hline Subtotal thyroidectomy & $2(12.5)$ & $0(0.0)$ & \\
\hline Total thyroidectomy & $13(81.3)$ & $33(97.1)$ & \\
\hline Lymphadenectomy & $5(31.3)$ & $9(26.4)$ & 0.900 \\
\hline Surgical re-intervention, $\mathrm{n}(\%)$ & $2(12.5)$ & $2(5.9)$ & 0.800 \\
\hline Received RAI treatment, n (\%) & $15(93.8)$ & $33(97.1)$ & 0.500 \\
\hline Tumor size, cm (SD) & $2.1(0.9)$ & $2.6(1.7)$ & 0.600 \\
\hline Multifocal tumor, n (\%) & $8(50.0)$ & $9(26.4)$ & 0.090 \\
\hline Bilateral tumor, n (\%) & $5(31.3)$ & $5(14.7)$ & 0.200 \\
\hline Positive margin status, n (\%) & $13(81.3)$ & $24(70.6)$ & 0.300 \\
\hline Lymphovascular invasion, n (\%) & $6(37.5)$ & $10(29.4)$ & 0.500 \\
\hline Perineural invasion, $\mathrm{n}(\%)$ & $0(0.0)$ & $1(2.9)$ & 1.000 \\
\hline Extrathyroid extension, n (\%) & $9(56.3)$ & $5(14.7)$ & $0.007^{\mathrm{b}}$ \\
\hline Lymph node metastases, n (\%) & $9(56.3)$ & $9(26.4)$ & $0.040^{\mathrm{b}}$ \\
\hline Distant metastases, n (\%) & $1(6.2)$ & $0(0.0)$ & 0.300 \\
\hline TNM staging, $\mathrm{n}(\%)^{\mathrm{a}}$ & & & $0.010^{\mathrm{b}}$ \\
\hline I & $5(31.3)$ & $19(55.9)$ & \\
\hline II & $1(6.2)$ & $8(23.5)$ & \\
\hline III & $2(12.5)$ & $6(17.6)$ & \\
\hline IV & $8(50.0)$ & $1(2.9)$ & \\
\hline Tumor stage III/IV, n (\%) & $10(62.5)$ & $7(20.5)$ & $0.009^{\mathrm{b}}$ \\
\hline
\end{tabular}

${ }^{a}$ TNM staging was performed according to the criteria of Edge et al (17). ${ }^{\mathrm{b} S i g n i f i c a n t}$ values $(\mathrm{P} \leq 0.05)$. TCV, tall cell variant; PTC, papillary thyroid carcinoma; CaFVs, classical and follicular variants; RAI, radioactive iodine; SD, standard deviation; TNM, tumor-node-metastasis.

Table II. Clinicopathological features in a PTC series according to the BRAF mutation status.

\begin{tabular}{|c|c|c|c|}
\hline Variable & $B R A F^{\mathrm{V} 600 \mathrm{E}}(\mathrm{n}=19)$ & $B R A F$ wild type $(\mathrm{n}=25)$ & P-value \\
\hline Age, years (SD) & $54.6(17.9)$ & $51.1(15.0)$ & 0.100 \\
\hline Tumor size, cm (SD) & $2.1(1.1)$ & $2.6(1.7)$ & 0.100 \\
\hline Multifocal tumor, n (\%) & $7(41.1)$ & $8(38.0)$ & 0.800 \\
\hline Bilateral tumor, n (\%) & $4(23.5)$ & $5(23.8)$ & 1.000 \\
\hline Positive margin status, n (\%) & $15(83.3)$ & $13(61.9)$ & 0.200 \\
\hline Lymphovascular invasion, $\mathrm{n}(\%)$ & $5(26.3)$ & $9(42.8)$ & 0.200 \\
\hline Perineural invasion, $\mathrm{n}(\%)$ & $1(5.2)$ & $0(0.0)$ & 0.400 \\
\hline Extrathyroid extension, n (\%) & $10(52.6)$ & $2(9.5)$ & $0.009^{\mathrm{a}}$ \\
\hline Lymph nodes metastases, n (\%) & $11(57.8)$ & $5(23.8)$ & $0.028^{\mathrm{a}}$ \\
\hline Advanced stage (III/IV), n (\%) & $14(73.6)$ & $9(42.8)$ & $0.049^{\mathrm{a}}$ \\
\hline Persistent-disease, n (\%) & $6(31.5)$ & $3(14.2)$ & 0.300 \\
\hline Disease-free survival, n (\%) & $11(57.8)$ & $18(85.7)$ & 0.100 \\
\hline
\end{tabular}

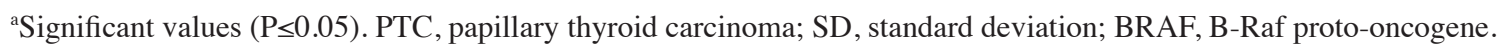

the patient with distant metastases at diagnosis, in the two patients developing metastases on follow-up, and in the two patients that succumbed to the disease, all of whom belonged to the TCV PTC series. 


\section{Discussion}

In the current study, the main clinicopathological features of the TCV of PTC were examined, the frequency of which appears to be rising along with the increased incidence of PTC worldwide $(19,20)$. However, the causes of this increased incidence of the TCV of PTC, and whether it is a true increase, remain to be elucidated. The TCV made up $~ 10 \%$ of all cases of PTC in the initial series studied by Hawk and Hazard (3); however, later studies on the incidence of this entity detected the TCV in between 1.3 and $13 \%$ of all PTC cases $(21,22)$. Similar to the findings of Ito et al (23), the current study detected 3.6\% of the TCV of PTC in a series of 437 PTC cases. This variation in the reported prevalence of TCV PTC may occur as a consequence of a poor definition of this variant due to the following factors: i) A variance in the height of the neoplastic cells depending on the plane of the section (6); ii) the presence of a significant proportion of tall cells in various types of PTC (6); iii) the differing diagnostic criteria proposed (for example, distinct threshold values in the percentage of tall cells required to determine a particular case of PTC as being a variant of tall cells) $(3,4,6)$; and iv) the misdiagnosis of this variant on routine pathological examination (7). Certain studies have revealed that 1-13\% of diagnosed cases of classical PTC were reclassified as TCV PTC following revision by endocrine pathologists $(13,24-27)$. The TCV of PTC has a $6 \%$ prevalence $(95 \%$ confidence interval, $4-7 \%$ ) in all PTC, following a pooling of the data from the literature (10). Although there is no consensus concerning the threshold of tall cells defining the TCV of PTC, LiVolsi (4) proposed to specify the presence of foci of tall cells in pathological reports irrespective of the percentage of tall cell cytology. Despite the lower number of cases in the current series, all cases of the TCV of PTC had $\geq 50 \%$ tall cells, which may indicate the increased reliability of the study.

Due to the clinical differences between the patients with the TCV of PTC and classical PTC, a control series with exactly the same mean age could not be obtained in the current study; however, no significant differences in patient age were detected between the two groups $(\mathrm{P}=0.1)$. The female:male ratio in the patients with TCV of PTC was 2.2, with females accounting for $69 \%$, and males $31 \%$ of cases. In the control group of patients in the present study, females accounted for $82 \%$, and males for $18 \%$ of cases. Certain studies have also observed that the TCV of PTC has a higher prevalence in males compared with classical PTC $(10,19,25)$. It is established that, in differentiated thyroid carcinoma cases, male patients tend to have more advanced disease diagnosed at an older age, lower disease-free survival and higher mortality compared with female patients $(28,29)$. The mean age at presentation of the patients in the present study with the TCV of PTC (57 years) was similar that to observed in a large population-based cancer registry (Surveillance, Epidemiology and End Results) from 1988-2008 (19). This data was also concordant with the ranges and mean age pooled from the series that has been previously reported (range, 41-66 years; mean, 50.1 years for TCV PTC; range, 34-53 years; mean, 45.7 years for classical PTC) (10). Age at diagnosis is also an important prognostic factor in patients with differentiated thyroid carcinoma (30) and, particularly after 40-45 years, the adverse effect of age on prognosis increases gradually with every decade (31).
The behavior of $\mathrm{TCV}$ is more aggressive than that of $\mathrm{CaFVs}$ of PTC $(3,8,10,12-14,23,24,27,30)$. Although there is a lack of consensus on whether the TCV of PTC is varied from the classical PTC in terms of tumor size at presentation (10), a previous review revealed that the mean tumor diameter in all cases of the TCV of PTC was $20 \mathrm{~mm}$, by comparison with $19 \mathrm{~mm}$ in classical PTC (10). The current series of the TCV of PTC was compared with the two CaFVs to determine if, irrespective of age and size, TCV is more aggressive than its classical and follicular counterparts. The overall percentage of multifocality, bilaterality, positive margins, vascular invasion, extrathyroidal extension, lymph node metastasis, distant metastasis and stage III/IV at presentation was greater in the TCV variant group, as compared with the classical and follicular PTC groups (Table I). Similar figures have been reported by previous studies, and the overall rates of multifocality, extrathyroidal extension, lymph node metastasis, and distant metastasis at the time of diagnosis in patients with TCV PTC were 45.7, 63.9, 59.0 and $8.6 \%$ respectively (10). The current study detected significantly higher rates of extrathyroidal extension (56.3 vs. $14.7 \%$; $\mathrm{P}=0.007)$, lymph node metastasis $(56.3$ vs. $26.4 \%$; $\mathrm{P}=0.04)$ and advanced-stage disease (62.5 vs. $20.5 \%$; $\mathrm{P}=0.009)$ in the TCV series in comparison with the CaFVs, and the tumor size was slightly larger in the latter group [ $21 \mathrm{~mm}(\mathrm{SD}, 0.9 \mathrm{~mm})$ vs. $26 \mathrm{~mm}$ (SD, $1.7 \mathrm{~mm}$ ), respectively]. A patient with distant metastases was present in the TCV of PTC group in the present study, but no distant metastases were detected in the control group. These findings were consistent with previous studies concerning the increased aggressiveness of TCV compared with the CaFVs of PTC, and support such aggressiveness being independent of tumor size and patient age.

$B R A F$ gene encodes a serine/threonine kinase that belongs to the RAS-RAF-mitogen-activated protein kinase (MAPK) kinase-extracellular signal-regulated kinase-mitogen activated protein kinase signaling pathway, the role of which is to mediate the cellular responses to growth factors. The T1796A $B R A F$ mutation, leading to the substitution of a valine by a glutamic acid at position 600 in exon 15, is the most prevalent mutation in PTC. The $B R A F^{\mathrm{V} 600 \mathrm{E}}$ mutation increases BRAF kinase activity, triggering the MAPK signaling pathway independent of the activation of upstream factors. The $B R A F^{V 600 E}$ mutation is the most frequent point mutation detected in PTC (36-83\%), with a strong genotype-phenotype association, and is almost exclusively detected in cases of PTC that exhibit a papillary or mixed papillary-follicular growth pattern $(32,33)$. Previous reports indicate that the $B R A F$ mutation has the highest prevalence in the TCV of PTC $(80-100 \%)(10,34)$. In the patient series of the current study, the percentage of cases exhibiting the $B R A F^{V 600 E}$ mutation was also significantly higher in the TCV of PTC group (80\%; $\mathrm{P}=0.004)$.

Certain studies have reported significant associations between $B R A F$-positive thyroid tumors and poor prognostic indicators, including male gender, increased age, lymph node metastases, extrathyroid extension, distant metastases, higher tumor staging, tumor size and tumor recurrence $(10,32)$. A retrospective multicenter study demonstrated that the $B R A F^{V 600 E}$ mutation was significantly correlated with increased cancer-associated mortality in patients with PTC; however, this association was not independent of a number of clinicopathological features of aggressiveness, including 
older patient age at diagnosis, lymph node metastases, extrathyroidal extension, distant metastasis or advanced disease (stage IV) (35). A recent meta-analysis demonstrated that $B R A F^{V 600 E}$-positive papillary thyroid types of microcarcinoma are more likely to possess aggressive clinicopathological characteristics (36). Subsequently, another previous study revealed that the coexistence of $B R A F^{V 600 E}$ and telomerase reverse transcriptase promoter mutations was particularly associated with high-risk clinicopathological features in PTC (37). Notably, in the current study, the $B R A F^{V 600 E}$ mutation was associated with extrathyroidal extension $(\mathrm{P}=0.009)$, lymph node metastases $(\mathrm{P}=0.028)$ and advanced stage $(\mathrm{P}=0.049)$ in the TCV of PTC and the CaFVs of PTC groups (Table II). In addition, all the patients that presented with distant metastases at diagnosis, that developed metastases on follow-up or that succumbed to the disease, had $B R A F^{V 600 E}$-positive TCV PTC. These results suggest that the $B R A F^{V 600 E}$ mutation functions in the aggressive biological behavior of the TCV of PTC. The current hypothesis, based on this series of clinically relevant PTC, is concordant with a previous study by Virk et al (38) on papillary microcarcinoma. In this previous study, Virk et al (38) proposed that the $B R A F^{V 600 E}$ mutation is an early event in thyroid carcinogenesis, and is associated with distinctive morphology and aggressive features, even in papillary thyroid microcarcinomas.

In conclusion, the present study reports a series of PTC strictly classified as the TCV ( $\geq 50 \%$ of tall cells) and reveals that, irrespective of patient age and tumor size, this variant is significantly associated with a higher rate of extrathyroidal extension, lymph node metastasis, advanced stage and $B R A F^{V 600 E}$ mutations, compared with the CaFVs of PTC. The higher rate of $B R A F^{\mathrm{V} 600 \mathrm{E}}$ mutations in the TCV of PTC compared with the classical and follicular counterparts, also supports the hypothesis of a role for these mutations in the aggressiveness of PTC.

\section{Acknowledgements}

The present study was supported by the Carlos III Health Institute, Ministry of Economy and Competitiveness (Madrid, Spain; grant no. PI15/01501-FEDER).

\section{References}

1. Davies L and Welch HG: Current thyroid trends in the United States. JAMA Otolaryngol Head Neck Surg 140: 317-322, 2014

2. Lam AK, Lo CY and Lam KS: Papillary carcinoma of thyroid: A 30-yr clinicopathological review of the histological variants. Endocr Pathol 16: 323-330, 2005.

3. Hawk WA and Hazard JB: The many appearances of papillary carcinoma of the thyroid. Cleve Clin Q 43: 207-215, 1976.

4. LiVolsi VA: Papillary carcinoma tall cell variant (TCV): A review: Endocr Pathol 21: 12-15, 2010.

5. Lastra RR, LiVolsi VA and Baloch ZW: Aggressive variants of follicular cell-derived thyroid carcinomas. A cytopathologis's perspective. Cancer Cytopathol 122: 484-503, 2014.

6. LiVolsi VA, Albores-Saavedra J, Asa SL, Baloch ZW, Sobrinho-Simões M, Wenig B, DeLellis RA, Cady B, Mazzaferri EL, Hay I, Fagin JA, et al: Papillary carcinoma. In: DeLellis RA, Heitz PU, Eng C (eds) Pathology and Genetics: Tumours of Endocrine Organs. 3rd edition. World Health Organization Classification of Tumours. France, IARC Press, Lyon, pp57-66, 2004.

7. Ghossein R and Livolsi VA: Papillary thyroid carcinoma tall cell variant. Thyroid 18: 1179-1181, 2008.
8. Ganly I, Ibrahimpasic T, Rivera M, Nixon I, Palmer F, Patel SG, Tuttle RM, Shah JP and Ghossein R: Prognostic implications of papillary thyroid carcinoma with tall-cell features. Thyroid 24 : 662-670, 2014

9. Dettmer MS, Schmitt A, Steinert H, Capper D, Moch H, Komminoth $\mathrm{P}$ and Perren A: Tall cell papillary thyroid carcinoma: New diagnostic criteria and mutations in BRAF and TERT. Endocr Relat Cancer 22: 419-429, 2015.

10. Wang X, Cheng W, Liu C and Li J: Tall cell variant of papillary thyroid carcinoma: Current evidence on clinicopathologic features and molecular biology. Oncotarget 7: 40792-40799, 2016.

11. Morris LG, Shaha AR, Tuttle RM, Sikora AG and Ganly I: Tall-cell variant of papillary thyroid carcinoma: A matched-pair analysis of survival. Thyroid 20: 153-158, 2010.

12. Johnson TL, Lloyd RV, Thompson NW, Beierwaltes WH and Sisson JC: Prognostic implications of the tall cell variant of papillary thyroid carcinoma. Am J Surg Pathol 12: 22-27, 1988.

13. Ghossein RA, Leboeuf R, Patel KN, Rivera M, Katabi N, Carlson DL, Tallini G, Shaha A, Singh B and Tuttle RM: Tall cell variant of papillary thyroid carcinoma without extrathyroid extension: Biologic behavior and clinical implications. Thyroid 17: 655-661, 2007.

14. Shi X, Liu R, Basolo F, Giannini R, Shen X, Teng D, Guan H, Shan Z, Teng W, Musholt TJ, et al: Differential clinicopathological risk and prognosis of major papillary thyroid cancer variants. J Clin Endocrinol Metab 101: 264-274, 2016.

15. Nikiforov YE, Seethala RR, Tallini G, Baloch ZW, Basolo F, Thompson LD, Barletta JA, Wenig BM, Al Ghuzlan A, Kakudo K, et al: Nomenclature revision for encapsulated follicular variant of papillary thyroid carcinoma: A paradigm shift to reduce overtreatment of indolent tumors. JAMA Oncol 2: 1023-1029, 2016

16. Gnemmi V, Renaud F, Do Cao C, Salleron J, Lion G, Wemeau JL, Copin MC, Carnaille B, Leteurtre E, Pattou F and Aubert S: Poorly differentiated thyroid carcinomas: Application of the Turin proposal provides prognostic results similar to those from the assessment of high-grade features. Histopathology 64: 263-273, 2014.

17. Edge SB, Byrd DR, Compton CC, Fritz AG, Greene FL and Trotti A: AJCC Cancer staging handbook, 7th edition. NY, Springer, New York, pp111-122, 2010.

18. Cameselle-Teijeiro J, Abdulkader I, Pérez-Becerra R, Vázquez-Boquete A, Alberte-Lista L, Ruiz-Ponte C, Forteza J and Sobrinho-Simões M: BRAF mutation in solid cell nest hyperplasia associated with papillary thyroid carcinoma. A precursor lesion? Hum Pathol 40: 1029-1035, 2009.

19. Kazaure HS, Roman SA and Sosa JA: Aggressive variants of papillary thyroid cancer: Incidence, characteristics and predictors of survival among 43,738 patients. Ann Surg Oncol 19: 1874-1880, 2012.

20. Ceresini G, Corcione L, Michiara M, Sgargi P, Teresi G, Gilli A, Usberti E, Silini E and Ceda GP: Thyroid cancer incidence by histological type and related variants in a mildly iodine-deficient area of Northern Italy, 1998 to 2009. Cancer 118: 5473-5480, 2012.

21. Guan H, Vandenbussche CJ, Erozan YS, Rosenthal DL, Tatsas AD, Olson MT, Zheng R, Auger M and Ali SZ: Can the tall cell variant of papillary thyroid carcinoma be distinguished from the conventional type in fine needle aspirates? A cytomorphologic study with assessment of diagnostic accuracy. Acta Cytol 57: 534-542, 2013.

22. Axelsson TA, Hrafnkelsson J, Olafsdottir EJ and Jonasson JG: Tall cell variant of papillary thyroid carcinoma: A population-based study in Iceland. Thyroid 25: 216-220, 2015.

23. Ito Y, Hirokawa M, Fukushima M, Inoue H, Yabuta T, Uruno T, Kihara M, Higashiyama T, Takamura Y, Miya A, et al: Prevalence and prognostic significance of poor differentiation and tall cell variant in papillary carcinoma in Japan. World J Surg 32: 1535-1545, 2008.

24. Terry JH, St John SA, Karkowski FJ, Suarez JR, Yassa NH, Platica CD and Marti JR: Tall cell papillary thyroid cancer: Incidence and prognosis. Am J Surg 168: 459-461, 1994.

25. Rüter A, Nishiyama R and Lennquist S: Tall-cell variant of papillary thyroid cancer: Disregarded entity? World J Surg 21: 15-21, 1997.

26. Michels JJ, Jacques M, Henry-Amar M and Bardet S: Prevalence and prognostic significance of tall cell variant of papillary thyroid carcinoma. Hum Pathol 38: 212-219, 2007. 
27. Bernstein J, Virk RK, Hui P, Prasad A, Westra WH, Tallini G, Adeniran AJ, Udelsman R, Sasaki CT, Roman SA, et al: Tall cell variant of papillary thyroid microcarcinoma: Clinicopathologic features with BRAF(V600E) mutational analysis. Thyroid 23: $1525-1531,2013$.

28. Gilliland FD, Hunt WC, Morris DM and Key CR: Prognostic factors for thyroid carcinoma. A population-based study of 15,698 cases from the Surveillance, Epidemiology and End Results (SEER) program 1973-1991. Cancer 79: 564-573, 1997.

29. Kilfoy BA, Devesa SS, Ward MH, Zhang Y, Rosenberg PS Holford TR and Anderson WF: Gender is an age-specific effect modifier for papillary cancers of the thyroid gland. Cancer Epidemiol Biomarkers Prev 18: 1092-1100, 2009.

30. SoaresP,Celestino R,Melo M,FonsecaEand Sobrinho-Simões M: Prognostic biomarkers in thyroid cancer. Virchows Arch 464: 333-346, 2014

31. Hay ID, Thompson GB, Grant CS, Bergstralh EJ, Dvorak CE Gorman CA, Maurer MS, McIver B, Mullan BP, Oberg AL, et al: Papillary thyroid carcinoma managed at the Mayo Clinic during six decades (1940-1999): Temporal trends in initial therapy and long-term outcome in 2444 consecutively treated patients. World J Surg 26: 879-885, 2002.

32. Erler P, Keutgen XM, Crowley MJ, Zetoune T, Kundel A, Kleiman D, Beninato T, Scognamiglio T, Elemento O,Zarnegar R and Fahey TJ III: Dicer expression and microRNA dysregulation associate with aggressive features in thyroid cancer. Surgery 156 : 1342-1350, 2014.
33. Sobrinho-Simões M, Máximo V, Rocha AS, Trovisco V, Castro P, Preto A, Lima J and Soares P: Intragenic mutations in thyroid cancer. Endocrinol Metab Clin North Am 37: 333-362, 2008.

34. Tavares C, Melo M, Cameselle-Teijeiro JM, Soares P and Sobrinho-Simões M: ENDOCRINE TUMOURS: Genetic predictors of thyroid cancer outcome. Eur J Endocrinol 174: R117-R126, 2016.

35. Xing M, Alzahrani AS, Carson KA, Viola D, Elisei R, Bendlova B, Yip L, Mian C, Vianello F, Tuttle RM, et al: Association between BRAF V600E mutation and mortality in patients with papillary thyroid cancer. JAMA 309: 1493-1501, 2013.

36. Li F, Chen G, Sheng C, Gusdon AM, Huang Y, Lv Z, Xu H Xing $\mathrm{M}$ and Qu S: BRAFV600E mutation in papillary thyroid microcarcinoma: A meta-analysis. Endocr Relat Cancer 22: 159-168, 2015.

37. Jin L, Chen E, Dong S, Cai Y, Zhang X, Zhou Y, Zeng R, Yang F, Pan C, Liu Y, et al: BRAF and TERT promoter mutations in the aggressiveness of papillary thyroid carcinoma: A study of 653 patients. Oncotarget 7: 18346-18355, 2016.

38. Virk RK, Van Dyke AL, Finkelstein A, Prasad A, Gibson J, Hui P, Theoharis CG, Carling T, Roman SA, Sosa JA, et al: BRAFV600E mutation in papillary thyroid microcarcinoma: A genotype-phenotype correlation. Mod Pathol 26: 62-70, 2013 